\title{
CARACTERIZACIÓN DE GALLINAS BATSI ALAKEN LAS TIERRAS ALTAS DEL SURESTE DE MÉXICO
}

\author{
CHARACTERIZATION OF HENS BATSI ALAKIN THE HIGHLANDS OF \\ SOUTHEASTMEXICO
}

\author{
Zaragoza, M.L. ${ }^{*}$; Rodríguez H., J.V. ${ }^{\text {; }}$ Hernández Z., J.S. ${ }^{2}$; Perezgrovas, G.R. ${ }^{3}$; \\ Martínez C., B. ${ }^{1}$ y Méndez E, J.A. ${ }^{1}$ \\ ${ }^{1}$ Colegio de Posgraduados. Campus Puebla. México. *zaragoza67@hotmail.com \\ ${ }^{2}$ Instituto de Ciencias. Benemérita Universidad Autónoma de Puebla. México. \\ ${ }^{3}$ Instituto de Estudios Indígenas. Universidad Autónoma de Chiapas. México.
}

\section{Palabras clave adicionales}

Cultura local. Peso corporal. Plumaje. Recursos genéticos locales.

\section{RESUMEN}

Se caracterizaron zoométricamente 508 gallinas adultas (132 machos y 376 hembras) de 9 comunidades en 3 municipios de Los Altos de Chiapas. Se realizó observación directa y obtención del peso y medidas corporales. Las plumas fueron predominantemente de tonalidades oscuras $(68,3 \%)$, trigueñas $(14,4 \%$ ) y blancas $(10 \%)$. El plumaje es normal $(97,8 \%)$ o rizado $(2,17 \%)$ y con cuello desnudo $(6,29 \%)$ o emplumado $(93,7$ $\%)$, tarsos con plumas $(8,66 \%)$, con copetes $(35,8 \%)$ y con plumas en mejillas y copetes $(7,48$ $\%)$. Las crestas son sencillas (87\%) o en rosa $(11,6 \%)$. El color de la piel fue principalmente blanco $(56,8 \%)$ o amarillo (41,7\%). Los ojos fueron principalmente de color naranja $(64,56 \%)$ o amarillo (21\%). El peso promedio de las hembras fue de $1900 \pm 376$ g (CV: 19,8\%), y el de los machos de $2300 \pm 630 \mathrm{~g}$ (CV: $27,6 \%$ ). Las medidas de los machos fueron mayores. Hubo correlación entre el peso y perímetro torácico para machos y hembras. La gran variabilidad permitiría la creación de líneas productivas con rusticidad y la conservación de sistemas de producción tradicionales, cultural y socialmente sustentables en poblaciones indígenas.

\section{SUMMARY}

A study was conducted for zoometric characterization of 508 adult hens (132 males and

\section{AdDitiOnAL KEYWORDS}

Body weight. Local culture. Local genetics resources. Plumage.

376 females) from nine communities in three municipalities from Los Altos de Chiapas region (Chiapas highlands). Description was obtained by direct observation, weight and corporal measurements. Feathers colors is diverse, but the tonalities predominant are dark ( $68.3 \%$ ), brunettes $(14.4 \%)$ or white $(10 \%)$. The plumage is normal $(97.8 \%)$ or curled $(2.17 \%)$, with naked neck (6.29 $\%)$, feathered neck $(93.7 \%)$, feathered shank $(8.66 \%)$, fringed $(35.8 \%)$ and feathered cheeks and fringed $(7.48 \%)$. The comb shape is simple ( 87 $\%)$ or rose type $(11.6 \%)$. The skin was predominantly white $(56.8 \%)$ or yellowish $(41.7$ $\%)$. The eyes presented an orange $(64.5 \%)$ or yellow $(21 \%)$ color. The average weight of females was $1900 \pm 376 \mathrm{~g} \mathrm{(CV:} 19.8 \%)$ and of males was $2280 \pm 630 \mathrm{~g}$ (CV: $27.8 \%$ ). Measurements were larger in males whit high variability. High correlations between weight and thoracic perimeter for males and females were found. This variability involves a biological richness and may be a great potential for the creation of rustic productive lines for Los Altos de Chiapas region in the highlands of Chiapas, Mexico.

\section{INTRODUCCIÓN}

La producción animal de bajos insumos es una práctica popular entre las comunidades rurales. Las gallinas desempeñan fun- 
ciones socioeconómicas dentro de la religión y como pagos o regalos, siendo consideradas una fuente importante de ingresos económicos, sobre todo para la población femenina (Segura, 1989; Rodero et al., 1992; Swatson et al., 2001; Mwalusanya et al., 2002; Tadelle et al., 2003; McAinsh et al., 2004; Muchadeyi et al., 2004; Zaman et al., 2004). Las mujeres son las principales propietarias y se encargan de administrar, vender y recibir dinero por las ventas de estos animales en las familias (Mengesha et al., 2008).

En México, a las gallinas que nacen dentro de las parvadas locales se reconocen e identifican como gallinas de rancho, gallinas criollas, gallinas de patio, de solar o de traspatio y otros nombres más locales. Ampliamente distribuidas por las zonas rurales son más frecuentes que otras especies y permiten la diversificación de la producción y aumentan la seguridad alimentaria de las familias.

En las comunidades indígenas y campesinas del país, las gallinas son criadas en sistemas extensivos, con una alimentación basada en pastoreo en libertad y pocos suplementos alimenticios. Los alojamientos o gallineros son variados según la disponibilidad económica de los propietarios y también se define por el entorno ecológico local que permite la disponibilidad de material para la construcción (Perezgrovas, 2006).

Aún se carece de información sobre las condiciones de este colectivo, necesarias para la planificación de actividades de conservación y promoción de los recursos genéticos animales. El objetivo de este trabajo fue describir mediante la evaluación zoométrica, la población local de gallinas de las tierras altas del sureste mexicano.

\section{MATERIAL YMÉTODOS}

La región de Los Altos posee una superficie de $2413 \mathrm{~km}^{2}$ que equivale al $5 \%$ de la superficie total de estado. Geográficamente, es una cadena de montañas que nace en
Guatemala y penetra, con dirección SE-NW, al territorio de México. La temporada de lluvias (1200 mm al año) se inicia en mayo y concluye en octubre, con la máxima precipitación $(250 \mathrm{~mm})$ en el mes de septiembre (INEGI, 2007). La mayor parte de la topografía es abrupta pero se observa una diversidad de relieves: valles, mesetas y declives con pendientes suaves y fuertes. La altitud regional varía de 1200 a 2760 msnm y el clima predominante es el templado-subhúmedo $\mathrm{C}$ (W2) (W), con lluvias en verano, de acuerdo con la clasificación de Köppen modificada por García (1973).

Se llevó a cabo una encuesta formal en diversas comunidades de tres municipios de la región, empleando una cédula de registro para obtener las características morfológicas y mediante evaluación visual se registraron las características fenotípicas de las gallinas. Paralelamente, se generaron discusiones abiertas con mujeres, hombres y adultos mayores para conocer las expectativas de la producción avícola. Con base en los resultados de la encuesta inicial, un total de nueve comunidades en tres municipios fueron finalmente elegidas. En cada comunidad, los hogares fueron elegidos al azar y, utilizando la metodología de bola de nieve se fueron sumando de manera voluntaria algunos propietarios más.

\section{CARACTERIZACIÓNZOOMÉTRICA}

Los animales utilizados para la caracterización, fueron adultos nacidos en la parvada o adquiridas en las comunidades periféricas, en total 508 gallinas de las localmente conocidas como batsi alak (que en idioma tsotsil significa nuestras gallinas). Los datos cuantitativos se obtuvieron utilizando una báscula digital, un pie de rey con precisión de $0,02 \mathrm{~mm}$ y una cinta métrica. Los atributos fanerópticos se describieron mediante la observación visual.

La recolección de datos se centró en la observación del sexo y peso del animal, así como en las características de coloración de la cresta, barbillas, ojos, piel y tarsos. La 


\section{CARACTERIZACIÓN DE GALLINAS LOCALES EN CHIAPAS, MÉXICO}

forma, tamaño y pigmentación en orejillas, cresta, pico y tarsos. Se tomaron también las longitudes del cuello, dorsal y ventral del cuerpo, del ala (proximal, media y distal), del fémur, tarso y dedo medio, así como del espolón y el perímetro torácico.

Las medidas fueron tomadas individualmente y anotadas en una ficha descriptiva que consideró entre otras características, las recomendadas de FAO (1987), y se realizaron como se indica en la tabla $\mathbf{I}$.

El peso vivo fue medido con una báscula digital con capacidad de $10 \mathrm{~kg}$ y precisión de $10 \mathrm{~g}$. Las variables cualitativas registradas para cada gallina fueron:

- En la cabeza: tipo y color de cresta, color de ojo, forma de la orejilla, color de pico, color de barbilla, presencia o ausencia de copete.

- En cuello: presencia o ausencia de plumas.

- En el cuerpo: color y tipo de plumas.

- En las patas: color de tarsos, presencia o ausencia de plumas y espolón.

\section{ANÁlISIS ESTADÍSTICO}

Fue empleada la estadística descriptiva para determinar la dispersión de los datos

Tabla I. Medidas corporales consideradas para la caracterización de la gallina local de Las Tierras Altas de Chiapas. (Body measurements considered for the characterization of local hens of Chiapas Highlands).

Longitud de la cabeza (LCa)

Anchura de la cabeza (ACa)

Longitud de pico (LP)

Ancho de la cresta (ACR)

Longitud de cresta ( $\mathrm{LCr}$ )

Longitud de cuello (LCU)

Longitud dorsal (LD)

Longitud ventral (LV)

Distancia entre articulaciones

fémuro-ílio-isquiático (DAFL)

Perímetro de tórax (PT)

Longitud ala proximal (húmero) (LH)

Longitud ala media (radio-cúbito) (LRC)

Longitud ala distal (falanges) (LFS)

Longitud de muslo (fémur) (LF)

Longitud de pierna (tibia) (LT)

Ancho de pierna (tibia) (CT)

Longitud tarso-metatarso (caña) (LTM)

Longitud dedo medio ( $3^{\text {a }}$ falange) (LF3)

Longitud de espolón (1 $1^{\text {a }}$ falange) (LF1)
Distancia entre el punto más sobresaliente del occipital y el hueso frontal (lagrimal)

Distancia entre los puntos más salientes del borde supra orbital del frontal

En dirección caudo-craneal, en la base del pico hasta la punta del mismo

Abarca el espacio en dirección dorso ventral

Se toma en dirección cráneo - caudal

Distancia comprendida de la base de la nuca hasta el encuentro

Desde la primera vértebra torácica hasta la región del pigostillo (cola)

Medida en la región esternal (quilla)

Se tomó la circunferencia del tórax bajo las alas y en la región de proyección del esternón

La longitud de ala se tomó desde la unión del húmero con la columna vertebral en tres segmentos: húmero (ala proximal), radio y cubito (ala media) metacarpo (ala distal) Distancia entre las región media del coxal hasta la articulación de la rodilla

Distancia entre las articulaciones de rodilla y tarso

Distancia entre la articulación del tarso y el origen del cuarto dedo

Distancia entre el calcáneo y el tobillo

Según Lázaro (2006) y Estrada (2007). 
ZARAGOZA, RODRÍGUEZ, HERNÁNDEZ, PEREZGROVAS, MARTÍNEZY MÉNDEZ

Tabla II. Distribución del color de las plumas en la gallina local de Las tierras Altas de Chiapas. (Color distribution of the plumage in local hens of Chiapas Highlands).

\begin{tabular}{lcccccc}
\hline $\begin{array}{l}\text { Color del } \\
\text { plumaje }\end{array}$ & Frecuencia & $\%$ & Frecuencia & $\%$ & Hembras y machos \\
& & & & \multicolumn{2}{c}{ Machos } \\
$\%$
\end{tabular}

cualitativos; los datos cuantitativos fueron sometidos a análisis de varianza, seguido por análisis de correlación y de regresión. Las pruebas fueron realizadas utilizando el programa SPSS versión 15.0.

\section{RESULTADOSYDISCUSIÓN}

El color del plumaje es muy variado (tabla II). El negro es el más común entre las hembras $(35,1 \%)$ y jaspeado para los machos $(35,6 \%)$. Otros colores frecuentes son el trigueño, barrado y blanco.

En la tabla III, se observa que el tipo de plumaje es mayoritariamente normal $(97,8$ $\%)$, mientras que las plumas rizadas $(2,17 \%)$ apenas registradas en hembras, fueron más frecuentes en los machos.

La mayoría de los animales presenta emplumado de tipo normal $(93,7 \%)$ siendo pocos los casos de cuello desnudo $(6,3 \%)$. Los copetes o penachos (machos, $32,6 \%$ y hembras, $44,9 \%$ ), son plumas que crecen justo detrás de la cresta. La presencia de plumas en las mejillas en combinación con copetes se presentó tanto en hembras $(7,4$ $\%)$ y machos $(7,6 \%)$. La frecuencia de tarsos

Tabla III. Tipo y distribución de las plumas en la gallina local de Los Altos de Chiapas. (Type and distribution of the plumage in local hens of Chiapas Highlands).

\begin{tabular}{lcccccc}
\hline & \multicolumn{2}{c}{ Hembras } & \multicolumn{2}{c}{ Machos } & \multicolumn{2}{c}{ Hembras y machos } \\
Características & Frecuencia & $\%$ & Frecuencia & $\%$ & Frecuencia & $\%$ \\
\hline Tipo de plumas & & & & & & \\
Normales & 372 & 74,8 & 125 & 25,1 & 497 & 97,8 \\
Rizadas & 4 & 0,8 & 7 & 1,4 & 11 & 2,1 \\
total & 376 & & 132 & & 508 & \\
Distribución del plumaje & & & & & & 32 \\
Cuello desnudo & 24 & 6,3 & 8 & 3,4 & 476 & 93,7 \\
Cuello emplumado & 352 & 93,6 & 124 & 94,7 & 44 & 8,6 \\
Tarso emplumado & 23 & 6,1 & 21 & 15,9 & 182 & 35,8 \\
Copetes & 139 & 44,9 & 43 & 32,5 & 38 & 7,4 \\
Mejillas y copetes & 28 & 7,4 & 10 & 7,5 & & \\
\hline
\end{tabular}

Archivos de zootecnia vol. 62, núm. 239, p. 324. 


\section{CARACTERIZACIÓN DE GALLINAS LOCALES EN CHIAPAS, MÉXICO}

Tabla IV. Tipo y color de la cresta en la gallina local de Los Altos de Chiapas. (Type and color of the combs in local hens of Chiapas Highlands).

\begin{tabular}{|c|c|c|c|c|c|c|}
\hline \multirow{2}{*}{$\begin{array}{l}\text { Tipo de cresta } \\
\text { y color }\end{array}$} & \multicolumn{2}{|c|}{ Hembras } & \multicolumn{2}{|c|}{ Machos } & \multicolumn{2}{|c|}{ Hembras y machos } \\
\hline & Frecuencia & $\%$ & Frecuencia & $\%$ & Frecuencia & $\%$ \\
\hline Guisante & 2 & 0,5 & 0 & 0 & 2 & 0,4 \\
\hline Sin cresta & 2 & 0,5 & 0 & 0 & 2 & 0,4 \\
\hline Nuez & 3 & 0,8 & 0 & 0 & 3 & 0,6 \\
\hline Rosa & 30 & 8,0 & 29 & 22,0 & 59 & 11,6 \\
\hline Simple & 339 & 90,1 & 103 & 78,0 & 442 & 87,0 \\
\hline Total & 376 & & 132 & & 508 & \\
\hline \multicolumn{7}{|c|}{ Coloración de la cresta } \\
\hline Sin cresta & 2 & 0,5 & 0 & 0 & 2 & 0,4 \\
\hline Negra & 4 & 1,0 & 0 & 0 & 4 & 0,7 \\
\hline Rojo & 71 & 18,8 & 68 & 51,5 & 139 & 27,3 \\
\hline Rojo tostado & 28 & 7,4 & 28 & 21,2 & 56 & 11,0 \\
\hline Rosa & 245 & 65,2 & 34 & 25,8 & 279 & 54,9 \\
\hline Vino & 27 & 7,1 & 2 & 1,5 & 29 & 5,7 \\
\hline Total & 376 & & 132 & & 508 & \\
\hline
\end{tabular}

emplumados fue menor en las hembras $(6,1$ $\%)$ que en los machos $(15,9 \%)$

La forma más frecuente de las crestas, fue en un $90 \%$ de tipo sencilla o de rosa $(8 \%)$ en las hembras mientras que para los machos fue de $78 \%$ con crestas normales y 22 $\%$ en forma de rosa (tabla IV).

Los colores predominantes de la cresta para el caso de las hembras fueron el rosa $(62,5 \%)$, rojo $(18,8 \%)$ y el rojo tostado (28 $\%)$; para el caso de los machos fue el color rojo $(51,5 \%)$, rojo tostado $(21,2 \%)$ y el rosa $(25,8 \%)$.

El color de las barbillas coincide con la coloración de la cresta, por tanto, se trata de los mismos porcentajes, las diferencias radican en la presencia o ausencia de pigmentación (tabla IV).

La piel de las aves presentó una coloración blanca en la mayoría de los casos, tanto para machos como en las hembras (tabla V), pero la presencia de piel amarilla y rosa también fue registrada, aunque en menor frecuencia. Por otro lado, el color de los tarsos (patas) se presentó en mayor proporción de color amarillo, negro, gris, blanco y otros.
La coloración de los ojos que se registró para las gallinas se presenta en la tabla VI, para el caso de las hembras van desde amarillo, café, gris, naranja, negro, rojo y hasta los casos raros de color verde; para los

Tabla $\boldsymbol{V}$. Color de piel y tarsos en la gallina local de Los Altos de Chiapas. (Color of skin and shank in local hens of Chiapas Highlands).

\begin{tabular}{lcccc}
\hline & $\begin{array}{c}\text { Hembras } \\
\text { Frecuencia }\end{array}$ & \multicolumn{2}{c}{ Machos } \\
& Frecuencia \% \\
\hline Color de piel & & & & \\
$\quad$ Amarilla & 161 & 42,8 & 51 & 38,0 \\
Blanca & 210 & 55,8 & 79 & 60,0 \\
Rosa & 5 & 1,4 & 2 & 2,0 \\
$\quad$ Total & 376 & & 132 & \\
Color de tarsos & & & & \\
Amarillo & 161 & 43,0 & 90 & 68,1 \\
Azul & 4 & 1,0 & 0 & 0 \\
Blanco & 24 & 6,0 & 4 & 3,1 \\
Gris & 63 & 17,0 & 8 & 6,1 \\
$\quad$ Negro & 108 & 29,0 & 24 & 18,1 \\
Rosa & 3 & 1,0 & 6 & 4,6 \\
Verde & 13 & 3,0 & 0 & 0 \\
Total & 376 & & 132 & \\
\hline
\end{tabular}


Tabla VI. Color de ojos y pico en las gallinas locales de Los Altos de Chiapas. (Color of eyes and beak in local hens of Chiapas Highlands).

\begin{tabular}{lcccc}
\hline & $\begin{array}{c}\text { Hembras } \\
\text { Frecuencia } \%\end{array}$ & \multicolumn{2}{c}{ Machos } \\
& Frecuencia \% \\
\hline Color de ojos & & & & \\
$\quad$ Amarillo & 80 & 21,3 & 27 & 20,5 \\
Café & 21 & 5,6 & 0 & 0 \\
Gris & 2 &, 5 & 0 & 0 \\
Naranja & 229 & 60,9 & 99 & 75 \\
Negro & 33 & 8,8 & 4 & 3 \\
Negro con rojo & 4 & 1,1 & 0 & 0 \\
Rojo & 5 & 1,3 & 0 & 0 \\
Verde & 2 &, 5 & 2 & 1,5 \\
Total & 376 & 100 & 132 & \\
Color de pico & & & & \\
Amarillo & 143 & 38 & 48 & 36,4 \\
Blanco & 6 & 1,6 & 5 & 3,8 \\
Café & 47 & 12,5 & 5 & 3,8 \\
Naranja & 5 & 1,3 & 0 & 0 \\
Negro & 175 & 46,5 & 74 & 56 \\
Total & 376 & & & 100 \\
\hline
\end{tabular}

machos, las coloraciones no fueron tan diversas.

Respecto al peso y medidas corporales, para el caso de los machos, los registros van de $1260 \mathrm{~g}$ hasta $4200 \mathrm{~g}$, mientras que para las hembras de 1020 hasta $3050 \mathrm{~g}$. Considerando la población de machos y hembras, se observa que los machos son un $17 \%$ más pesados que las hembras y al igual que el peso, algunas medidas corporales fueron significativamente mayores $(\mathrm{p}<0,01)$ para machos. En la tabla VII se muestran las principales características cuantitativas por sexo. Los coeficientes de variación para las medidas: ancho de cresta y longitud de cresta, longitud dorsal y longitud ventral así como longitud de tarso y de longitud de primera falange, indican alta variabilidad en la población de machos. Para el caso de las hembras, la dispersión se encuentra principalmente en las medidas longitud de primera falange, ancho de cresta así como para el ancho y largo de cabeza.

La tabla VIII con las correlaciones de
Pearson para machos y hembras muestran $55 \%$ de correlaciones significativas para machos, mientras que para el caso de las hembras hay $42,1 \%$ de correlaciones significativas $(\mathrm{p}<0,05)$.

Entre las variables zoométricas más importantes para los machos y que tienen alta correlación con el peso vivo aparecen, el perímetro torácico, longitud de la tibia y la longitud del fémur, mientras que para el caso de las hembras hay correlaciones entre el peso, la longitud de la tibia y el perímetro torácico. Pero como se puede apreciar y de acuerdo con los resultados de la significancia en las correlaciones para ambos sexos, las gallinas de estas comunidades representan una población con mucha variabilidad, lo que significa una riqueza biológica para estas comunidades.

\section{DISCUSIÓN}

La distribución de color en el plumaje de la población de gallinas locales de tierras altas de Chiapas, indica variabilidad genética derivada de la presencia de genes con diferentes efectos y a interacciones entre ellos (Periquet, 1997).

En la región, como réplica de las acciones gubernamentales en todo el país, por más de 30 años, se han dado procesos de sustitución de genotipos avícolas locales por otros mejorados, pero ajenos al entono y sin la adecuada supervisión técnica. Es para 1978, cuando el gobierno federal inició el programa de paquetes familiares, con el objetivo principal de mejorar el nivel nutricional de las comunidades marginadas. De esta manera millones de pollos de las razas Rhode Island Red, Plymouth Rock Barrado y Sussex, se han distribuido en el territorio nacional desde entonces (Berdugo, 1987).

El predominio del color negro en las gallinas locales de esta región, las convierte en las gallinas típicas de la comunidad ya que son las que sus propietarias llaman e identifican como batsi alak (nuestra galli- 


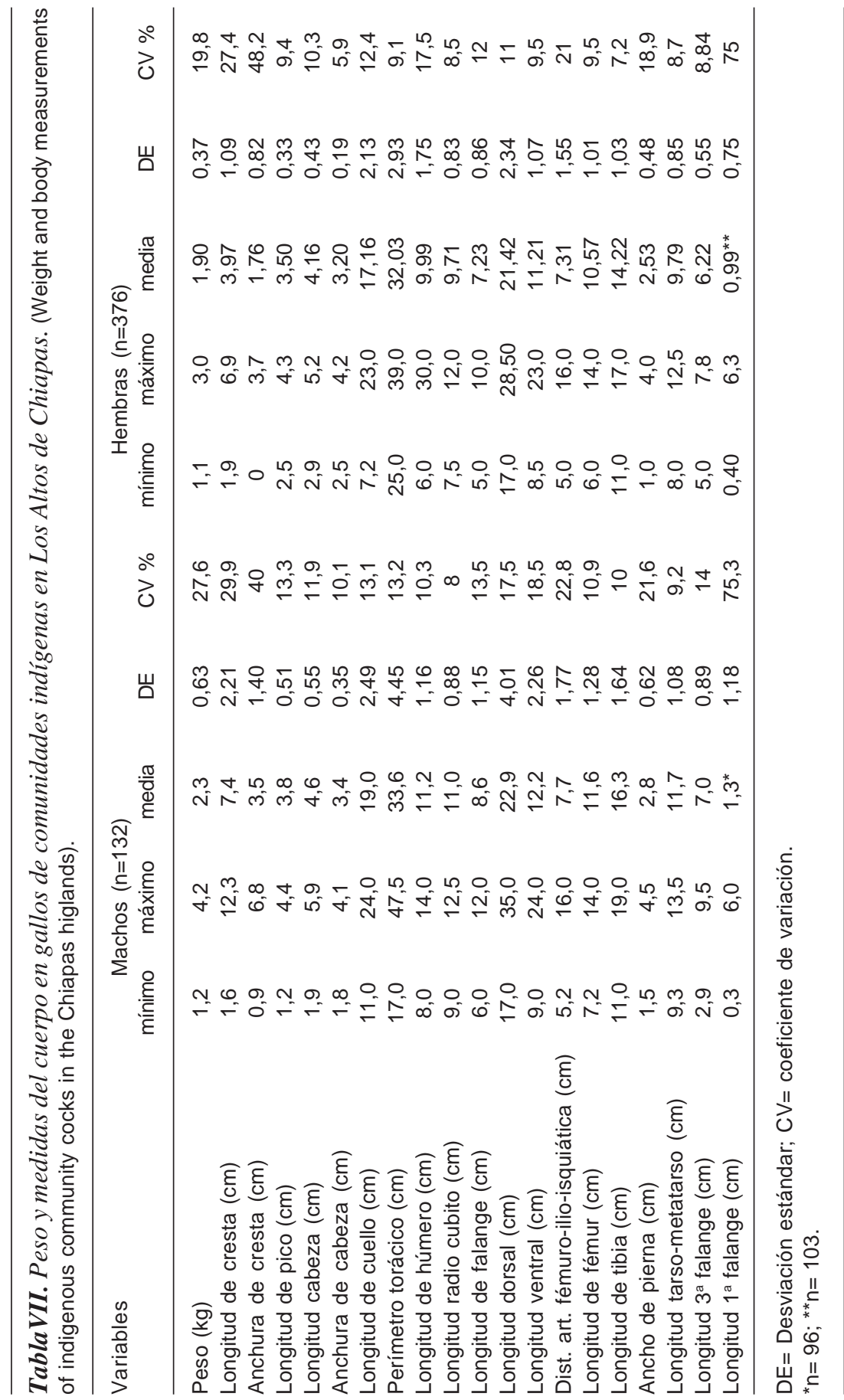

Archivos de zootecnia vol. 62, núm. 239, p. 327. 


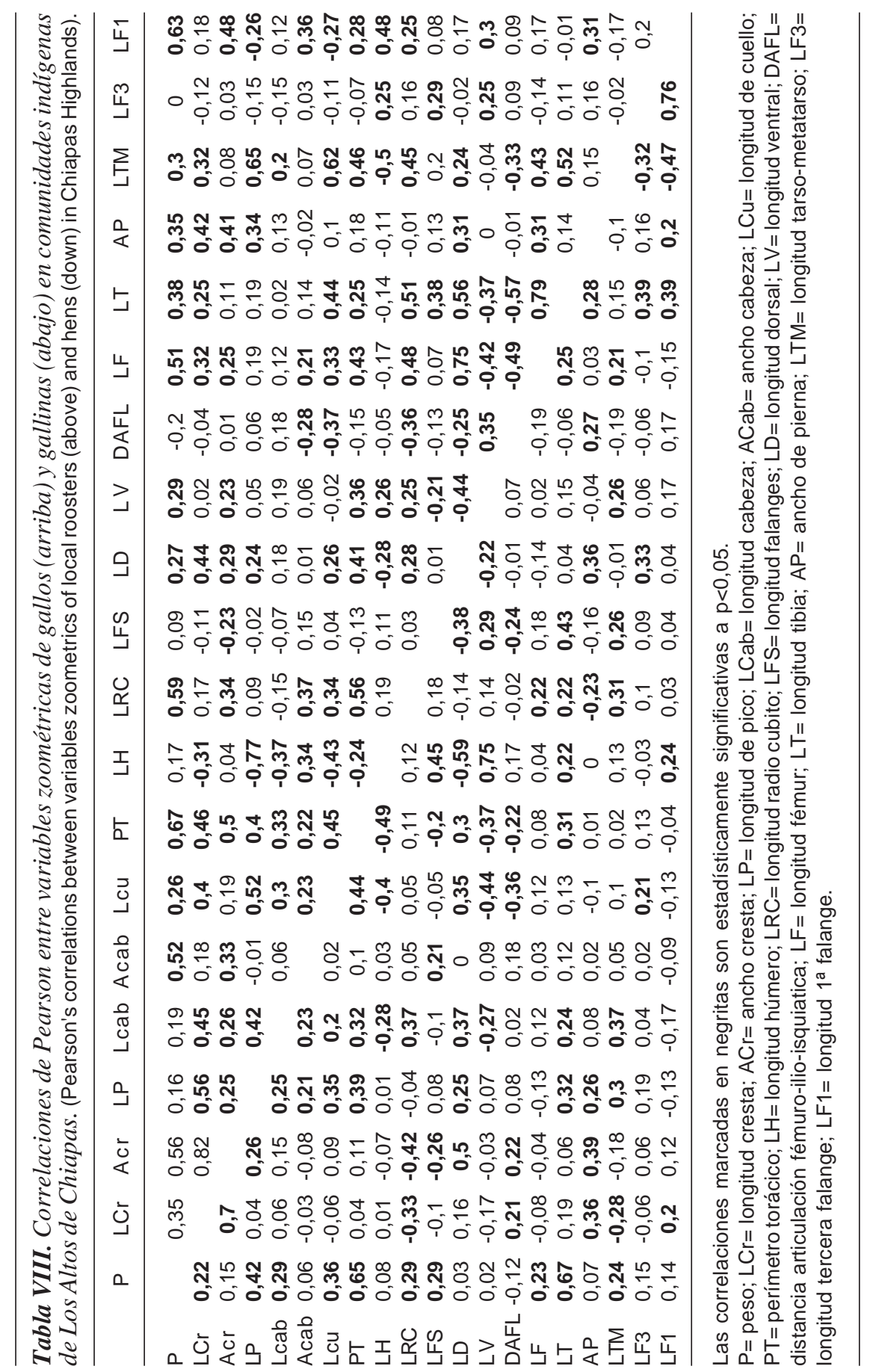


$n a$, en idioma tsotsil). Adoptarla como tal guarda una importante carga cultural por el hecho de ser parte de los insumos dentro de la medicina tradicional que se practica en esas comunidades. Sin embargo, los otros colores no les excluye de ser utilizados para los mismos ceremoniales, pero existen curanderos que basan la eficacia de sus servicios en el color de las gallinas. Al respecto, se puede apreciar que hay una selección de los propietarios dirigida por el color, pero al tiempo, las coloraciones más claras, entre los que se encuentra el blanco, el barrado y el jaspeado pueden estar relacionados con una dilución entre los genes locales con los introducidos mediante las razas comerciales, como sugieren Juárez et al. (2000).

En los resultados se puede observar que la distribución del plumaje refiere a la interacción genotipo $\mathrm{x}$ ambiente (Santoni et al., 2000; Bahy et al., 2003). Por lo que el emplume normal completo representa en gran medida el resultado de las condiciones geo-climáticas de las regiones altas de Chiapas. Las características de cuello desnudo asociado al gen $\mathrm{Na}(6,29 \%)$ y plumaje rizado asociado al gen $\mathrm{F}(2,17 \%)$, fueron observadas pero representan un porcentaje bajo en las parvadas visitadas. La baja presentación de dichos caracteres puede deberse a lo reportado por autores como AlAni et al. (1989); Horst y Mathur (1994); Juárez (1995); Guinbert (1997) y Van MarleKöster y Nel (2000), que mencionan que la presencia de estos genes provee de gran capacidad en los procesos fisiológicos bajo condiciones de elevada temperatura ambiental, para disipar el calor. Por lo que, la poca presentación de dichos genes puede deberse a las bajas temperaturas de las comunidades donde se realizó el trabajo, y porque las frecuencias genéticas son bajas y no se tiende a seleccionar, pues esto se da sólo por el ambiente.

A diferencia del cuello desnudo y plumaje rizado, los tipos morfológicos con gran presencia fueron: forma o tipo de la cresta y la presencia de plumas en la cabeza que semejan un penacho, conocido también como copete; las gallinas de las comunidades indígenas de Chiapas, también presentan tarsos emplumados en hembras como en machos y también plumas en mejillas y copetes. Cada una de estas características es identificada con nombres locales pero a las propietarias, les agrada tener en sus parvadas gallinas con estas características pues les consideran como rasgos de belleza, rareza y por consecuencia de diferencia con otras parvadas. Lo que significa una razón que justifica la presencia de esta diversidad.

La frecuencia de tarsos emplumados fue casi de $9 \%$, con este resultado se concuerda con lo referido por Juárez et al. (2000) en el sentido de que son diferentes los grupos genéticos que componen a la parvada mexicana actual y de que, para las tierras Altas de Chiapas, se fortalece la teoría de que la presencia de plumas en los tarsos es una característica de adaptación reminiscente de cuando las gallinas vivían en estado silvestre y que para defenderse de los predadores subían a los árboles con espinas para protegerse. Al respecto, en las comunidades indígenas de Chiapas, las parvadas de inicio no tienen un gallinero formal y en algunas no tienen un espacio exclusivo, por lo que duermen en árboles alrededor de la casa, por lo que probablemente esta característica persista no porque haya aparecido, sino porque esos genes existían en las poblaciones y que esta sea la razón de la diferencia a lo reportado por Juárez et al. (2000), que menciona 0,45\% para las comunidades que habitan alrededor del lago de Pátzcuaro en Michoacán, México.

La cresta sencilla y la forma de rosa fueron los tipos más encontrados, tanto en hembras como en machos; junto a la coloración de crestas, barbillas y orejas son características que sugieren la variabilidad de recursos genéticos de gallinas locales. En cuanto a la pigmentación de la piel y de los tarsos, se observa que no tienen relación. Para la piel, los colores mayormente reporta- 
dos fueron el blanco, amarillo y rosa, mientras que la coloración de las patas tiene un gran porcentaje en la coloración oscura que incluye desde el color gris, el verde, azul y el negro, a diferencia de los claros que incluye al amarillo y rosa. La presencia de color amarillo en las patas puede reflejar como lo refiere Juárez et al. (2000) el grado de penetración de genes diferentes a los locales en la población de gallinas de comunidades indígenas.

En cuanto a las medidas corporales, los valores más altos fueron los de los machos, resultados que coinciden con lo reportado por Azón y Francesh (1998); Missohou et al. (1998); Pérez et al. (2000) y Msoffe et al. (2002).

La preferencia por las gallinas locales es una razón importante dentro del sistema de vida de las familias indígenas de las comunidades de estudio, ya que, son insumos principales en la medicina tradicional, son el aporte inmediato de proteína a la nutrición de la familia y por último, representan una fuente de ingresos económicos por la venta de huevos y animales vivos. Entre las mujeres de la comunidad, mediante el obsequio de gallinas o huevos se fortalecen las relaciones sociales de la comunidad, situación que también ha sido reportada por McAinsh et al. (2004).

\section{CONCLUSIONES}

Al realizar la comparación entre sexos mediante las variables zoométricas se observaron diferencias importantes en machos y hembras para las variables: peso, longitud de cresta y ancho de cresta, perímetro torácico y longitud de tarso, que dejan ver a la población de machos como animales pesados, con crestas vistosas y de gran variabilidad en tamaño, en su mayoría de crestas sencillas, barbillas y orejillas más desarrolladas que las de las hembras y de colores brillantes en rojo o rojo tostado, como muestra del dimorfismo sexual.

La coloración del plumaje es predomi- nantemente oscura, lo que puede tener una explicación por las preferencias de esta tonalidad pues está asociada a las necesidades culturales del grupo tsotsil por su uso en ceremonias de la medicina tradicional. Existiendo selección a favor. Esa tonalidad oscura (que incluye a los individuos negros, rojos, jaspeados y barrados) les puede proporcionar a las gallinas un beneficio adicional, ya que puede servirles como camuflaje para ocultarse de los depredadores. En general se observa para las gallinas locales una gran variabilidad en cuanto a características morfológicas exteriores, sin embargo, la presencia de animales con plumajes claros y barrados, así como tarsos de color amarillo, son indicativo de la influencia de razas comerciales o especializadas.

La presencia de animales con tarsos emplumados (6 \% para hembras y $15,9 \%$ para los machos), así como de plumajes en forma de penachos y orejeras, aparte de ser motivo de elección y preferencia por las propietarias es una característica que hace suponer que esta población tiene una influencia de ancestros de razas asiáticas, ya que al no haber gallinas prehispánicas, las que fueron introducidas a la región tienen la influencia de las poblaciones de gallinas que llegaron al país.

La diversidad zoométrica y fenotípica en la población de gallinas de Los Altos de Chiapas, es sin duda un punto de partida para la realización de programas de fomento y conservación, así como por sus cualidades de resistencia a condiciones ambientales, la eficiencia para producir y por su uso en actividades socioculturales, características demandadas por el grupo indígena propietario. Sin embargo, es necesaria la realización de actividades de investigación para definir las mejores estrategias para el aprovechamiento de estos recursos animales, insertos en esta sociedad indígena.

De manera general, en las comunidades indígenas de Chiapas las gallinas son propiedad de las mujeres, lo que sugiere que capacitaciones y opciones de fomento de- 


\section{CARACTERIZACIÓN DE GALLINAS LOCALES EN CHIAPAS, MÉXICO}

ben estar encaminadas y dirigidas a ellas.

\section{AGRADECIMIENTOS}

A las mujeres propietarias de gallinas en

\section{BIBLIOGRAFÍA}

Al-Ani, I.A.; Al-Soudi, K.A.; Al-Obaidi, A.S.R. and Tarish, G.H. 1989. Dusting with chemicid and its effect on egg production and mortality of different breeds of chickens (local, Leghorn and New Hampshire) infested by yellow body louse (M. stranineus). J Agric Water Resour Res, Anim Prod, 8: 11-21.

Azón, R. y Francesch, A. 1998. La gallina del Sobrarbe: descripción y definición de una población de gallinas del pirineo de Huesca. Arch Zootec, 47: 461-465.

Bahy, A.A.; Mohammed, M.M.A. and Osama, M.A. 2003. Relationship between genetic similarity and some productive traits in local chicken strains. Afr J Biotechnol, 2: 46-47.

Berdugo, R.J. 1987. Estudio de la ganadería familiar en el municipio de Sucilá, Yucatán. Tesis de Maestría. Colegio de Posgraduados. Centro de Estudios de Desarrollo Rural. México. pp. 68-69.

Estrada, M.A. 2007. Caracterización fenotípica, Manejo y usos del pavo doméstico (Meleagris gallopavo, gallopavo) en la comunidad indígena de Kapola en la sierra nororiental del Estado de Puebla, México. Tesis de Maestría. Colegio de Posgraduados. $93 \mathrm{pp}$.

FAO. 1987. Banco de dato de recursos genéticos animales: 3. Descriptores de especies avícolas. Roma. Italia. Num. 59: 3.

García, E. 1973. Modificaciones al sistema de clasificación climática de Köppen. 2.ㄹ edición. UNAM. Instituto de Geografía.

Guinbert, E. 1997 Las estirpes cuello pelado. Rev Acontecer Avícola, 5: 17.

Horst, P. and Mathur, P.K. 1994. Feathering and adaptation to tropical climates. Proc. $9^{\text {th }}$ European Poultry Conference. Glasgow. 2: 79-82.

INEGI. 2007. Instituto Nacional de Estadística, Geografía e Informática. Agenda Estadística de los Estados Unidos Mexicanos. Aguascalientes, Ags. México.

Juárez, C.A. 1995. Producción de huevo, calidad de cascarón y balance de calcio en gallinas las comunidades indígenas que permitieron la manipulación de sus animales y su tiempo para compartir su conocimiento, al SIINVUNACH, a la SECAM y al CONACyT por el apoyo económico en la investigación.

criollas de cuello desnudo (Na). Rev Los Avicultores y su Entorno. México. 1: 20-22.

Juárez, C.A.; Manríquez, A.J.A. y Segura, C.J.C. 2000. Rasgos apariencia fenotípica en de aves de las zonas rurales los municipios de la Ribera del Lago de Pátzcuaro, Michoacán, México. Livest Res Rural Develop, 12(1). http://. cipav.org.co//rrd12/1/jua121.htm

Lázaro, G.C. 2006. Análisis del sistema de producción de gallinas de traspatio en La Trinidad Tianguismanalco, Tecali, Puebla. Tesis de Maestría. Colegio de Posgraduados. 93 pp.

McAinsh, C.V.; Kusina, J.; Madsen, J. and Nyoni, O. 2004. Traditional chicken production in Zimbabwe. Worlds Poultry Sci J, 60: 233-246.

Mengesha, M.; Tamir, B. and Tadelle, D. 2008. Socio-economical contribution and labor allocation of village chicken production of Jamma district, South Wollo. Ethiopia. Vol. 20. Article \#160. http://www.Irrd.org/lrrd20/10/meng20 160.htm (02/12/2010).

Missohou, A.; Sow, R.S. et Ngwe-Assoumou, C. 1998. Caractéristiques morphobiométriques de la poule du Sénégal. Anim Genet Resour Inf, 24: 63-69.

Muchadeyi, F.C.; Sibanda, S.; Kusina, N.T.; Kusina, J. and Makuza, S.M. 2004. The village chicken production system in Rushinga District of Zimbabwe. Livest Res Rural Develop, 16. http:/ /www.cipav.org.co//rrd//rrd16/6/much160 40.html

Msoffe, P.L.; Mtambo, M.M.; Minga, U.; Gwakisa, P.S.; Mdegela, R.H. and Olsen, J.E. 2002. Productivity and natural disease resistance potential of free-ranging local chicken ecotypes in Tanzania. Livest Res Rural Develop, 14(3). http://www.cipav.org.co//rrd//rrd14/3/msof 1 43.htm

Mwalusanya, N.A.; Katule, A.M.; Mutayoba, S.K. and Mtambo, M.M.A. 2002. Productivity of local chickens under village management conditions. Trop Anim Health Prod, 34: 405-416. 


\section{ZARAGOZA, RODRÍGUEZ, HERNÁNDEZ, PEREZGROVAS, MARTÍNEZY MÉNDEZ}

Pérez, A.P.G; Fernando, J.O.A.; Von Lengerken, G. y Pingel, H. 2000. La gallina Criolla de Cuba.1. Incubación y etapa inicial. El Arca, 4: 32-41.

Perezgrovas, R. 2006. Las razas autóctonas de animales domésticos: Patrimonio genético y cultural de Chiapas. Anuario CESMECA. pp. 107-123.

Periquet, J.C. 1997. Races de poulets, de l'élevage, produits d'hygiéne et de santé. Edition Broché. $112 \mathrm{pp}$.

Rodero, S.E.; Delgado, B. y Rodero, F. 1992. Aspectos económicos en la conservación de razas autóctonas en Andalucía. Arch Zootec, 41: 75-80.

Segura, C.J.C. 1989. Rescate genético y fomento avícola de las aves indias o criollas en México. Memorias de la Primera Reunión sobre Producción Animal Tropical; julio 27-29. Centro de Enseñanza, Investigación y Capacitación del Sureste. Cárdenas. Tabasco. pp. 44-46.

Santoni, S.; Faivre-Rampant, P.; Prado, E. et Prat D. 2000. Marqueurs moléculaires pour l'analyse des ressources génétiques et l'amélioration des plantes. Ressources génétiques, Cahiers
d'Agriculture, 9: 311-327.

Swatson, H.K.; Nsahlai, I.V. and Byebwa, B. 2001. The status of smallholder poultry production in the Alfred District of Kwazulu-Natal. South Africa: priorities for intervention. Livestock Community and Environment. Proc. $10^{\text {th }}$ Conference of the Association of Institutions for Tropical Veterinary Medicine. Copenhagen. Tadelle, D.; Million, T.; Alemu, Y. and Peters, K.J. 2003. Village chicken production systems in Ethiopia: 1. Flock characteristics and performance. Livest Res Rural Develop, 15 (1). http:// www.cipav.org.co/lrrd//rrd15/1/tadea151.html Van Marle-Köster, E. and Nel, L.H. 2000. Genetic characterization of native southern African chicken populations: evaluation and selection of polymorphic microsatellite markers. South Afr $J$ Anim Sci, 30: 1-6.

Zaman, M.A., Sorensen, P. and Howlider, M.A.R. 2004. Egg production performances of a breed and three crossbreeds under semi-scavenging system of management. Livest Res Rural Develop. 16. art \#60. http://www.cipav.org.co/ Irrd/Irrd16/8/zama16060.htm (30/11/2010).

Archivos de zootecnia vol. 62, núm. 239, p. 332. 